\title{
A Modified Microbial Adhesion to Hydrocarbons Assay to Account for the Presence of Hydrocarbon Droplets
}

\author{
Revised and re-submitted to: \\ Journal of Colloid and Interface Science
}

December 2, 2009

CAROLINE WARNE ZOUEKI ${ }^{1}$, NATHALIE TUFENKJII ${ }^{1}$, SUBHASIS GHOSHAL 2,*

\author{
${ }^{1}$ Department of Chemical Engineering, Mc Gill University, \\ Montreal, Quebec H3A 2B2, Canada \\ ${ }^{2}$ Department of Civil Engineering, McGill University, \\ Montreal, Quebec H3A 2K6, Canada
}

*Corresponding Author.Phone: (514) 398-6867; Fax: (514) 398-7361; E-mail: subhasis.ghoshal@mcgill.ca 


\begin{abstract}
The Microbial-Adhesion-to-Hydrocarbons (MATH) assay has been used widely to characterize microbial cell hydrophobicity and/or the extent of cell adhesion to hydrophobic liquids. The classical MATH assay involves spectrophotometric absorbance measurements of the initial and final cell concentrations in an aqueous cell suspension that has been contacted with a hydrocarbon liquid. In this study, microscopic examination of the aqueous cell suspension after contact with hexadecane or a hexadecane/toluene mixture revealed the presence of hydrocarbon droplets. The hydrocarbon droplets contributed to the absorbance values during spectrophotometric measurements and caused erroneous estimates of cell concentrations and extents of microbial adhesion. A modified MATH assay that avoids such artefacts is proposed here. In this modified assay, microscopic examination of the aqueous suspension and direct cell counts provides cell concentrations that are free of interference from hydrocarbon droplets. The presence of hydrocarbon droplets was noted in MATH assays performed with three bacterial strains, and two different hydrocarbons, at ionic strengths of $0.2 \mathrm{mM}$ and $20 \mathrm{mM}$ and $\mathrm{pH}$ 6. In these experiments, the formation of quasi-stable hydrocarbon droplets cannot be attributed to the presence of biosurfactants, or stabilization by biocolloids. The presence of surface potential at the hydrocarbon-water interface that was characterized by electrophoretic mobility of up to -1 and $-2 \otimes \mathrm{mcm} / \mathrm{Vs}$, likely caused the formation of the quasi-stable hydrocarbon droplets that provided erroneous results using the classical MATH assay.
\end{abstract}

Keywords: microbial adhesion, cell hydrophobicity, surface potential, emulsion stability, hexadecane, toluene. 


\section{Introduction}

The Microbial Adhesion to Hydrocarbons (MATH) assay was developed over 25 years ago, by Rosenberg et al. [1]. It has traditionally been used as a measure of microbial cell surface hydrophobicity [2-4]. The classical protocol involves vortexing a bacterial suspension in the presence of a test liquid hydrocarbon. Ideally, during this process the hydrocarbon breaks up into small droplets, some microorganisms adhere to the droplets and then rise with the hydrocarbon droplet during droplet coalescence and phase segregation. The fraction of adhering microorganisms is evaluated by comparing the initial and final absorbance values of the aqueous microbial suspension.

The MATH assay is used widely. In the medical field, Loughlin et al. [5] monitored cell surface properties of the nosocomial pathogen Pseudomonas aeruginosa as it grew resistant to the disinfectant benzalkonium chloride. From MATH experiments, they observed that the strain OO14 increased in hydrophobicity as the cells grew in resistance to the disinfectant. Bos and Busscher [6] used the assay to determine that the presence of divalent calcium cations increased adhesion of tooth colonizers (Streptococcus oralis and Actinomyces naeslundii) to hexadecane and chloroform. Within the context of environmental bioremediation, much research has been performed to evaluate the relationship between microbial cell surface hydrophobicity as quantified by the MATH assay, and the ability to degrade hydrocarbons $[7,8]$. For example, using the MATH assay, Zhang and Miller [7] observed that the presence of rhamnolipids increased cell surface hydrophobicity for slow octadecane degraders, but had no effect on fast degraders among several Pseudomonas aeruginosa strains. Microbial cell hydrophobicity is an important factor influencing microbial adhesion on 
various surfaces and several studies on transport of pathogenic or pollutant degrading bacteria in subsurface porous media have employed the MATH assay $[9,10]$.

Although the MATH assay is widely used as a measure of hydrophobicity, some have shown that it correlates poorly with other hydrophobicity assays [11]. Busscher et al. [12] have shown that it measures a combination of forces, such as electrostatic and Liftshitz-van der Waals interactions, as well as various short-range forces. It has been argued that the MATH assay is a measure of hydrophobicity only if the surfaces in question are uncharged [13]. Rosenberg, who had introduced this method in 1980, has since suggested that experiments be performed at high ionic strengths to minimize electrostatic effects [14]. Therefore, when it is performed at the isoelectric point, with a high ionic strength, or when the surfaces are not charged, the MATH assay is a hydrophobicity assay. Otherwise, the MATH assay is simply valid as an adhesion test and used as such by some researchers $[15,16]$.

In this study, we examine the application of the MATH assay to evaluate adhesion of selected bacteria to two hydrocarbon liquids, pure $n$-hexadecane and a $50 \% \mathrm{v} / \mathrm{v} n$-hexadecane and toluene mixture. The presence of hydrocarbon droplets in the aqueous microbial suspension after vortexing was noted, and the errors this may cause in estimation of microbial adhesion in the classical MATH assay was assessed. Furthermore, we propose a modified approach to quantify bacterial adhesion to hydrocarbons using a direct cell counting method.

The formation of stable or quasi-stable hydrocarbon droplets after vortexing during the MATH assay is likely, even in the absence of surfactants. Several studies have measured significant zeta potentials at the non-polar alkane oil-water interfaces, and attribute the surface potential to 
adsorption of hydroxyl ions [17]. The adsorption of hydroxyl ions, or other anions from the aqueous phase, and weak van der Waals forces between droplets contribute to the stability of nonpolar oil droplets in aqueous solutions. The magnitude of the oil droplet zeta potentials depend on the $\mathrm{pH}$ and ionic strength of the aqueous phase [18]. Furthermore, several studies have demonstrated that bacteria or non-biological colloids stabilize hydrocarbon droplets $[19,20]$. Thus it appears that there is a need to develop a MATH test that can reduce errors associated with the presence of oil droplets in the aqueous suspension.

\section{Materials and Methods}

\subsection{Solution Chemistry and Cleaning Procedure}

Analytical reagent grade chemicals were used throughout and Milli-Q deionised (DI) water was used to prepare all solutions. Electrolyte solutions were prepared with $0.2 \mathrm{mM}$ and $20 \mathrm{mM}$ $\mathrm{NaCl}$ (Sigma) at $\mathrm{pH}$ 6. All experiments were performed at room temperature $\left(20 \pm 1^{\circ} \mathrm{C}\right)$. The cleaning procedure for glassware in contact with hydrocarbons was to rinse with acetone, wash with DI water, then acid-wash with $12 \mathrm{M} \mathrm{HCl}$ and finally to flush repeatedly with DI water. The glassware that had not been in contact with hydrocarbons was simply acid-washed. The use of soap was avoided to ensure that the MATH assay was not affected by the presence of chemical surface active agents. 


\subsection{Preparation of Bacteria}

Pseudomonas aeruginosa ATCC 27853, Pseudomonas putida F1G4 and Mycobacterium kubicae ATCC 700732 were used in this study. The species were selected for their environmental relevance as they are known hydrocarbon degraders and/or naturally present in soils [21-24]. The bacteria were plated onto Luria-Bertani (LB) agar plates from frozen stocks kept at $-80^{\circ} \mathrm{C}$. Single colonies were used to inoculate cultures in $150 \mathrm{~mL} \mathrm{LB}$ broth at $37^{\circ} \mathrm{C}$ and $200 \mathrm{rpm}$ gyratory shaking. After 18 hrs of growth (to late stationary phase), cells were harvested by centrifuging $25 \mathrm{~mL}$ of the culture (Sorvall RC6) for $15 \mathrm{~min}$ at $5860 \mathrm{~g}$ in an SS-34 rotor (Kendro). The growth medium was decanted, and the pellet was resuspended in the $0.2 \mathrm{mM} \mathrm{NaCl}$ electrolyte solution at $\mathrm{pH}$ 6. To remove traces of the growth medium, the cells were centrifuged and resuspended in fresh electrolyte one additional time to obtain a final bacterial suspension for use in the MATH assays.

\subsection{Hydrocarbons}

MATH assays were performed with the aliphatic petroleum hydrocarbon $n$-hexadecane (Sigma, purity $\geq 99 \%$ ) and a mixture of $50 \% \mathrm{v} / \mathrm{v} n$-hexadecane/toluene (Sigma) was used as the second MATH assay hydrocarbon. Toluene was chosen since it is commonly present petroleum fuels and to investigate adhesion to a hydrocarbon of considerable difference in hydrophobicity to $n$ hexadecane. The octanol-water partition coefficient for hexadecane $\left(\log \mathrm{K}_{\mathrm{ow}}=8.25\right)$ is much larger than that of toluene $\left(\log \mathrm{K}_{\mathrm{ow}}=2.69\right)$ [25]. Both hexadecane and toluene have been used extensively as model solvents in studies on colloid and interface science relating to petroleum fuels. 


\subsection{Classical MATH Assay}

A similar method to the one described by Rosenberg et al. [1] was used for the MATH assay. The bacterial suspension was adjusted to an absorbance $\left(A_{\mathrm{o}}\right)$ of 1.0 at $600 \mathrm{~nm}$, using an Agilent 8453 UV-Visible spectrophotometer. In a clean borosilicate round-bottom glass tube $(16 \times 150 \mathrm{~mm})$, $300 \mu \mathrm{L}$ of the test hydrocarbon was added to $5 \mathrm{~mL}$ of bacterial suspension. The tube was vortexed for $2 \mathrm{~min}$ (vortex mixer, setting 8, Fisher Scientific) and set aside to rest for $15 \mathrm{~min}$ to allow for phase separation. Next, a sample of the bacterial suspension was retrieved with a clean Pasteur pipet, while taking great care to avoid taking in the hydrocarbon layer into the pipet. The sample was then transferred to a quartz measurement cell for the final absorbance measurement $\left(A_{\mathrm{f}}\right)$ at $600 \mathrm{~nm}$. Adhesion of bacteria to the hydrocarbons was evaluated as the fraction partitioned to the hydrocarbon phase, $F P_{\mathrm{C}}$. This was calculated as $\left(F P_{\mathrm{C}}=1-A_{\mathrm{f}} / A_{\mathrm{o}}\right)$.

\subsection{Modified MATH Assay}

Instead of measuring the absorbance of the bacterial suspension, the initial bacterial concentration in the bacterial suspension was set using a Helber counting chamber (Z30000, Hawksley), viewed under a microscope (IX71, Olympus) operating in phase contrast mode at 10× magnification. Specifically, the concentration of the stock bacterial suspension was first evaluated using the Helber counting chamber, and then adjusted to $5 \times 10^{7}$ cells $/ \mathrm{mL}$ by diluting with fresh electrolyte. The same protocol as the classical MATH assay was followed for addition of the hydrocarbon to the cell suspension, vortexing, settling of the two phases, and for sampling the bacterial suspension in the aqueous phase. A sample of the aqueous bacterial suspension was 
carefully retrieved using a Pasteur pipet, and $10 \mu \mathrm{L}$ of this sample was transferred to the Helber cell counting chamber. The grid lines spaced $50 \mu \mathrm{m}$ apart were used to establish a counting grid for cell enumeration. The hydrocarbon droplets and cells were easily distinguishable, ensuring true counts of bacteria not adhered to hydrocarbon phase. The fraction partitioned to the hydrocarbon phase was calculated as $\left(F P_{\mathrm{N}}=1-C_{\mathrm{f}} / C_{\mathrm{o}}\right)$, where $C_{\mathrm{o}}$ is the cell concentration in the bacterial suspension before mixing and $C_{\mathrm{f}}$ is the cell concentration of bacteria in the aqueous phase after vortexing and phase separation.

\section{Results and Discussion}

\subsection{Artefacts in the Classical MATH Assay Resulting from Presence of Hydrocarbon Droplets}

The classical MATH assay was used to examine adhesion of three different bacteria (Pseudomonas aeruginosa, Pseudomonas putida and Mycobacterium kubicae) to two hydrocarbon systems: pure nhexadecane $(\mathrm{H})$, and a $50 \% \mathrm{v} / \mathrm{v} n$-hexadecane/toluene mixture (HT). Results from the classical MATH assay are presented in Figure 1a. 

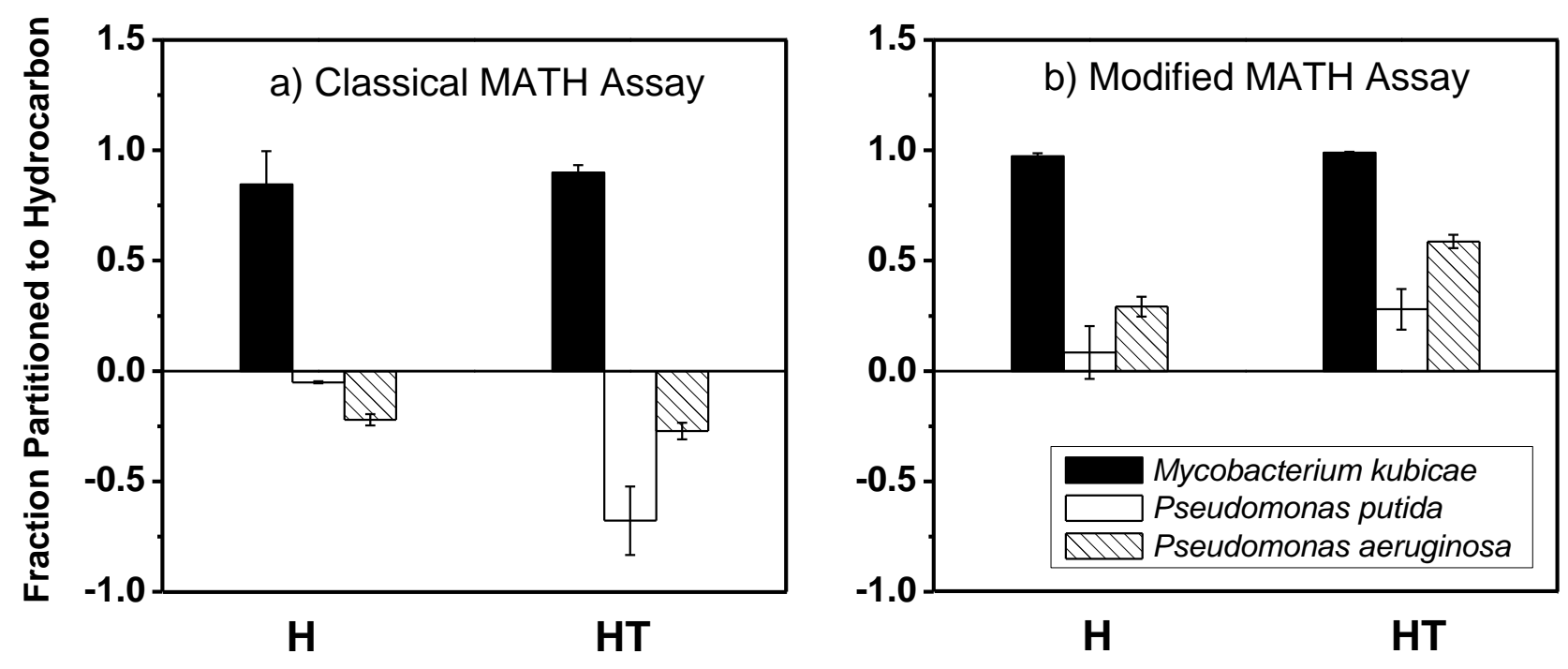

FIGURE 1. (a) Fraction of cells partitioned to the hydrocarbon phase measured using classical MATH assay, and (b) fraction of cells partitioned to the hydrocarbon phase measured using the modified MATH protocol. Bacterial suspensions are contacted with either hexadecane $(H)$ or a 50/50 hexadecaneltoluene mixture (HT). Cells were suspended in $0.2 \mathrm{mM} \mathrm{NaCl}$ at $\mathrm{pH} 6$ for all measurements $(5$ replicate measurements were made for each experimental condition).

Mycobacterium kubicae exhibits a significant extent of adhesion to both hydrocarbon systems examined ( $84.5 \%$ of cells partitioned to $\mathrm{H}$ and $90.0 \%$ of cells partitioned to HT). In contrast, however, Pseudomonas putida and Pseudomonas aeruginosa both demonstrate negative partitioning fractions in the two hydrocarbon systems (Figure 1a). Based on the approach used to evaluate adhesion to the hydrocarbon phase, a negative partitioning fraction suggests an increase in the absorbance of the bacterial suspension after the mixing and phase separation period. When conducting a MATH assay, the microbial cells adhering to hydrocarbon droplets rise to the oil/water interface during phase separation. The cell concentration in the bulk aqueous bacterial suspension is therefore expected to decrease or remain constant following mixing of the two phases, not to increase 
as shown here. Certainly, the observed apparent increase in cell concentration after phase mixing is not a physical possibility.

The cause for this increase in absorbance was investigated through the use of a microscope operating in phase contrast mode. Samples of the bacterial suspension used for the $A_{\mathrm{f}}$ absorbance measurements (i.e. taken after mixing and phase separation) were placed on a clean quartz microscope slide and viewed at 20× magnification. Microscope images for all three microorganisms revealed the presence of hydrocarbon droplets in the aqueous suspension, where 15 min was given for phase separation (Figure 2). After allowing 7 hours for phase separation, hydrocarbon droplets were still observed in the suspension, although in smaller quantities. The presence of hydrocarbon droplets within the bacterial suspension affected the absorbance measurements, leading to an overestimation of the final absorbance values $\left(A_{\mathrm{f}}\right)$, thereby significantly underestimating the fractions of cells partitioned to the hydrocarbon phase $\left(F P_{\mathrm{C}}\right)$. Indeed, such errors in the determination of the final cell content of the bacterial suspensions result in negative $F P_{\mathrm{C}}$ values for both Pseudomonas putida and Pseudomonas aeruginosa (Figure 1a). An increase in absorbance of the aqueous suspension after vortexing and phase separation, compared to the initial absorbance of the cell suspension has also been reported elsewhere [26]. 

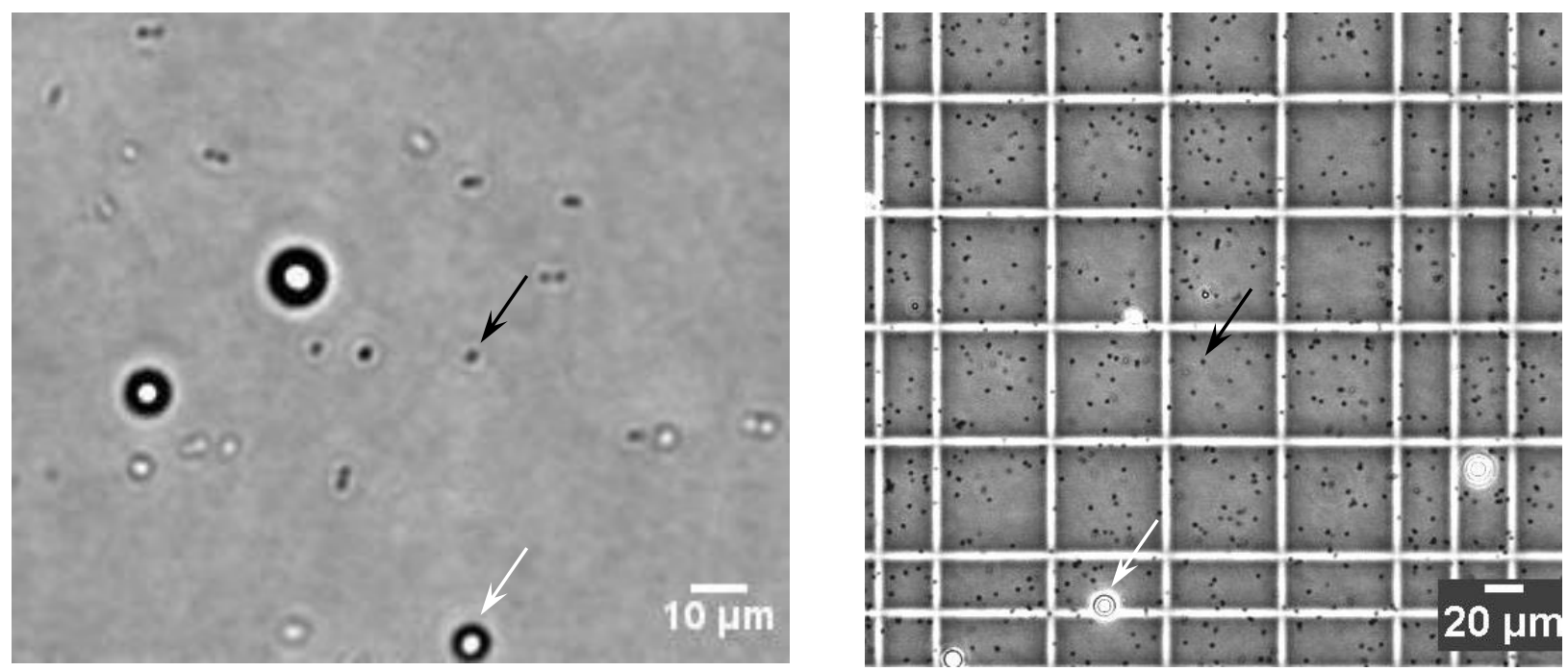

FIGURE 2. (a) Microscope image of hydrocarbon droplets stabilized in a Mycobacterium kubicae suspension ( $0.2 \mathrm{mM} \mathrm{NaCl}$, pH 6) after phase separation step in MATH assay. (White cells are slightly out of focus). (b) Microscope image of hydrocarbon droplets stabilized in a suspension of Pseudomonas putida placed on a Helber cell counting chamber $(0.2 \mathrm{mM} \mathrm{NaCl}, \mathrm{pH}$ 6) after phase separation step in MATH assay. White arrows point to hydrocarbon droplet. Black arrows point to bacterial cells.

To avoid the erroneous effect caused by hydrocarbon droplets present in the bacterial suspension, the modified protocol for the MATH assay described earlier (Section 2.5) was employed. Instead of using absorbance measurements to determine the bacteria concentration in the cell suspension, direct counting of non-adhered bacteria was used and this enabled visual discrimination from hydrocarbon droplets. Figure $2 \mathrm{~b}$ shows a microscope image of a suspension of Pseudomonas putida containing droplets of hexadecane placed in a Helber cell counting chamber. In this image, hydrocarbon droplets and cells are easily distinguished, ensuring that only bacteria are considered in the calculations of the partitioning fractions to the hydrocarbon phase.

The fractions of cells partitioned to the hydrocarbon phase were evaluated using the same Mycobacterium kubicae, Pseudomonas putida and Pseudomonas aeruginosa cell suspensions that were used for the experiments presented in Figure 1a. This time, the cell concentrations were determined 
using the Helber counting chamber. The results of the modified MATH assay are presented in Figure 1b. Comparable results are obtained for Mycobacterium kubicae using the two MATH protocols (solid bars). Mycobacterium cells exhibit considerable partitioning to the hydrocarbon phase when either the $n$-hexadecane $(\mathrm{H})$ or $n$-hexadecane/toluene $(\mathrm{HT})$ mixtures are used. The results obtained from the modified MATH protocol are particularly interesting for the two Pseudomonas species. In Figure $1 \mathrm{~b}$, the data clearly show that measurements obtained using the Helber counting chamber do not yield negative partitioning fractions $\left(F P_{\mathrm{N}}\right)$. Rather, the results show that the fraction of Pseudomonas putida that partitions to the hydrocarbon phase (open bars) is $8.4 \%$ for $\mathrm{H}$ and $28.0 \%$ for $\mathrm{HT}$, in contrast to the negative values obtained with the classical MATH protocol $(-5.1 \%$ for $\mathrm{H}$ and $-67.8 \%$ for HT). Similarly, measurements obtained with Pseudomonas aeruginosa in Figure $1 \mathrm{~b}$ further demonstrate that erroneous conclusions can be drawn with regards to cell adhesion and hydrophobicity, as hydrocarbon droplets cannot be distinguished from cells in absorbance measurements. 


\subsection{Effects of Ionic Strength on the Classical and Modified MATH Assays}

The data shown in Figure 1a were obtained at low ionic strength conditions $(0.2 \mathrm{mM}$ $\mathrm{NaCl}$ ). Several researchers have used the MATH assay results to draw conclusions about cell hydrophobicity, and it has been pointed out that MATH assay results obtained at low ionic strength do not account for cell hydrophobicity [12-14]. Hydrocarbon droplets are more likely to be stabilized at low ionic strength, where repulsive electrostatic interactions rather than hydrophobic interactions play a significant role in particle-particle interactions. The classical MATH assay was repeated using Pseudomonas putida cells suspended in $20 \mathrm{mM} \mathrm{NaCl}$ at $\mathrm{pH} 6$ (Figure 3a). However, even at $20 \mathrm{mM} \mathrm{NaCl}$, the partitioning fractions $\left(F P_{\mathrm{C}}\right)$ in Figure 3a are not be accurate, due to the formation of hydrocarbon droplets in the cell suspension. 

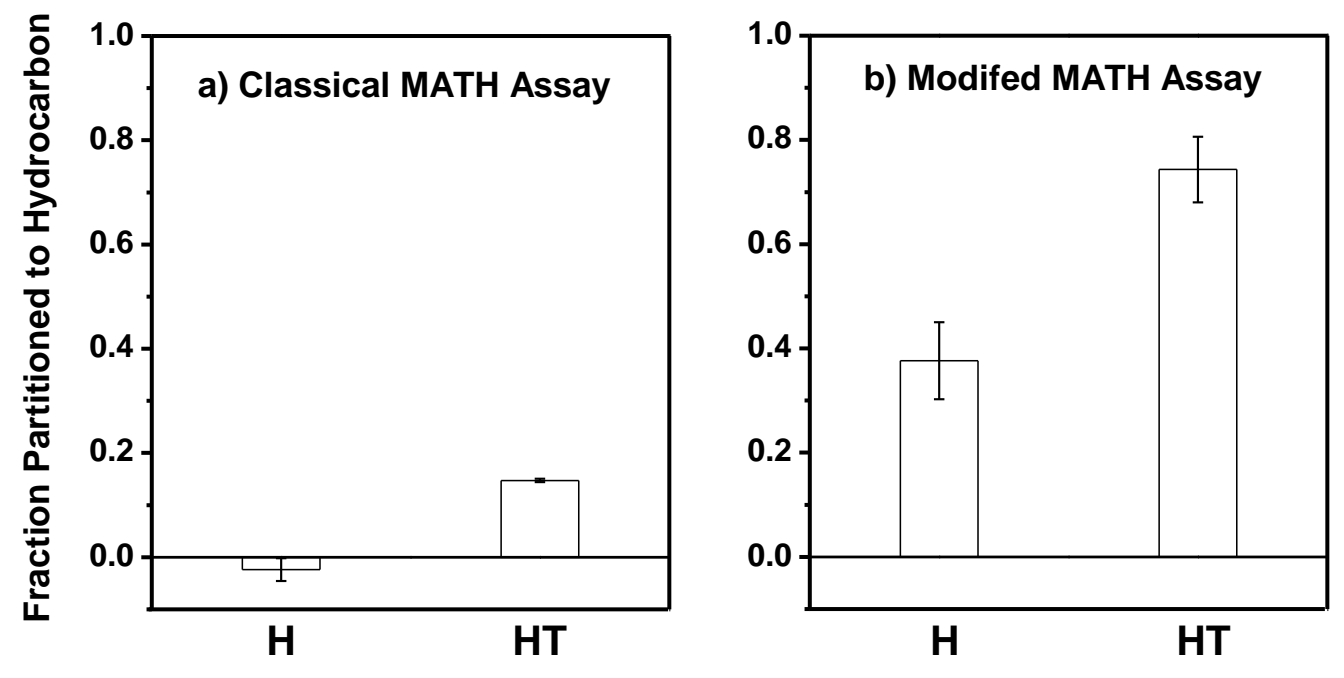

FIGURE 3. (a) Fraction of Pseudomonas putida cells partitioned to the hydrocarbon phase measured using classical MATH assay, and (b) fraction of Pseudomonas putida cells partitioned to the hydrocarbon phase measured using modified MATH protocol. Cells were suspended in $20 \mathrm{mM} \mathrm{NaCl}$ at $\mathrm{pH} 6$ for all measurements.

The formation of hydrocarbon droplets was confirmed by microscopic examination of a Pseudomonas putida cell suspension following a MATH experiment with $n$-hexadecane in $20 \mathrm{mM}$ $\mathrm{NaCl}$. The image reveals the presence of hydrocarbon droplets in the cell suspension even at this higher ionic strength. Although the $F P_{C}$ values determined from absorbance measurements at 20 $\mathrm{mM} \mathrm{NaCl}$ in Figure $3 \mathrm{a}$ are not negative as they were at $0.2 \mathrm{mM} \mathrm{NaCl}$, the $F P_{\mathrm{C}}$ values may actually be lower than the true extent of partitioning due to the erroneous effect of the hydrocarbon droplets. Indeed, the partitioning fractions evaluated using the modified $\mathrm{MATH}$ assay at $20 \mathrm{mM} \mathrm{NaCl}$ (Figure $3 \mathrm{~b}$ ) confirm that the $F P_{\mathrm{C}}$ values determined from absorbance measurements are artificially low.

Comparison of Figures 1 and 3 reveals an increase in the extent of bacterial adhesion to the hydrocarbon phase when cells are suspended in a higher ionic strength solution. This observed 
behaviour can be attributed to the reduction in repulsive electrical double layer interactions between cells and hydrocarbon droplets, due to double layer compression at higher ionic strengths [27].

\subsection{Possible Causes for Hydrocarbon Droplet Stabilization}

It is of interest to investigate the cause for hydrocarbon droplet stabilization. The stability of hydrocarbon droplets in aqueous suspensions has been attributed to the presence of a potential at their surface $[17,18]$. The electrophoretic mobility of hexadecane and hexadecane-toluene mixture droplets in an aqueous solution of $0.2 \mathrm{mM} \mathrm{NaCl}$ adjusted to $\mathrm{pH}$ of 6 , was measured, and was found to be between -1 and $-2 \unrhd \mathrm{mcm} / \mathrm{Vs}$ [28]. The surface potential on the hydrocarbon droplets is a contributing factor to the stabilization of the hydrocarbon droplets.

Some studies have shown that colloids can stabilize hydrocarbon droplets via steric hindrance of droplet coalescence [29]. It has been demonstrated that emulsion stability increases with colloid particle size, up to the order of a few microns [30]. The ability of stabilizing oil-in-water emulsions has also been observed with microorganisms in several studies, although the efficiency in stabilizing emulsions is found to vary with cell surface properties, such as cell surface hydrophobicity as measured by contact angles and the presence of fimbriae [19, 20]. It is possible that in our study hydrocarbon droplets present in the bacterial suspensions were stabilized during MATH assays due to the microorganisms, but given that stable droplets were also observed to form in cell-free extracts (as discussed below), this was not the predominant contributing factor in the formation of droplets that contributed to errors in estimating cell concentrations in the MATH assays. 
Alternatively, the occurrence of hydrocarbon droplets stabilized in the aqueous phase may be attributed to the presence of surface active agents; but as described previously, the cleaning procedure utilized in this study and the selection of high purity reagents ensured the absence of chemical surfactants in the solutions. Another possible explanation for the stabilization of oil droplets in the bacterial suspension is the release of biosurfactants by the microorganisms examined.

To verify whether biosurfactants were produced, aqueous bacterial suspensions were prepared in the same manner as for MATH assays in $0.2 \mathrm{mM} \mathrm{NaCl}$, cells were removed from the bacterial suspensions by centrifugation, and surface tension measurements were performed on the cell-free supernatants. If biosurfactants were released by the microorganisms a lower surface tension for the cell-free supernatant would be expected in comparison to the fresh electrolyte $(0.2 \mathrm{mM}$ $\mathrm{NaCl}$. Surface tension measurements were performed on cell-free supernatants and fresh electrolyte using a tensiometer K12 (Krüss) in conjunction with a Dosimat 655 (Metrohm). The variation in surface tension values of the fresh electrolyte was $70.8-74.1 \mathrm{mN} / \mathrm{m}$ and similar to that of the cell-free supernatant surface tension values $(71.5-73.0 \mathrm{mN} / \mathrm{m})$. Thus biosurfactants were not present under the MATH assay conditions employed. 


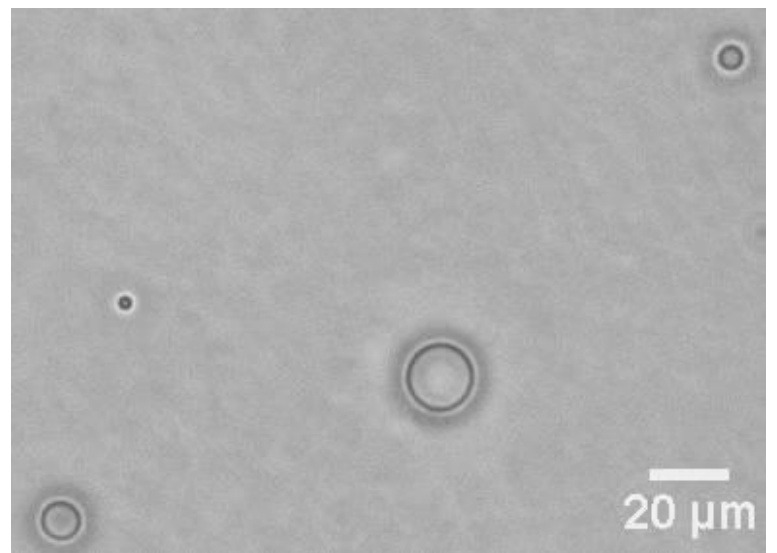

FIGURE 4. Microscope image of hydrocarbon droplets stabilized in Pseudomonas putida cell-free supernatant ( $0.2 \mathrm{mM} \mathrm{NaCl}$, pH 6) after phase separation step in MATH assay.

An experiment was designed as an alternative method to determining whether bacteria were the cause for hydrocarbon droplet stabilization. In a clean borosilicate round-bottom glass tube, 300 $\mu \mathrm{L}$ of the test hydrocarbon was added to $5 \mathrm{~mL}$ of cell-free supernatant (obtained by centrifugation of a washed aqueous bacterial suspension as used in the MATH assay). After vortexing this mixture and allowing $15 \mathrm{~min}$ for phase separation, the aqueous phase (i.e., cell-free supernatant) was carefully retrieved with a Pasteur pipet and observed under the microscope. A microscope image of hexadecane droplets stabilized by Pseudomonas putida cell-free supernatant is shown in Figure 4. Similar droplets were observed by vortexing the hydrocarbons with electrolyte solutions of $0.2 \mathrm{mM}$ and $20 \mathrm{mM}$. Droplets were also observed with deionized water, although to a lesser extent. This indicates that the presence of bacteria or colloids is not required for formation of the hydrocarbon droplets during the MATH assay. 


\section{Conclusions}

In this study we have identified an important source of artefact with the classical MATH assay; namely, the presence of oil droplets in the cell suspension. To overcome this limitation, we have proposed a modified protocol which involves cell enumeration. Direct cell counting using a Helber counting chamber allows for the determination of cell partitioning to the hydrocarbon phase by discriminating between cells and hydrocarbon droplets. Accounting for the interference in absorbance measurements of the cell suspension, following vortexing and phase separation, resulted in large differences in the estimation of fraction partitioned to hydrocarbons, in two of the three bacterial strains tested with hexadecane and a hexadecane-toluene mixture, at a $\mathrm{pH}$ of 6 . 


\section{Acknowledgements}

This research was supported by NSERC Discovery Grants awarded to N.T. and S.G., the McGill India Strategic Research Initiative (MISRI), a Eugenie Ulmer Lamothe award to C.W.Z., and the CRC and CFI Programs. The authors acknowledge S. Mukherji (IIT-Bombay) and G. Mohanty (McGill) for helpful discussions, R. Roy (McGill) for performing surface tension measurements, and M. Assanta (AAFC) for providing ATCC 27853 and ATCC 700732. 


\section{References}

[1] M. Rosenberg, D. Gutnick, E. Rosenberg, FEMS Microbiol. Lett. 9 (1980) 29.

[2] D.F. Gerson, J. Akit, Biochim. Biophys. Acta. 602 (1980)

[3] M.C. van Loosdrecht, J. Lyklema, W. Norde, G. Schraa, A.J. Zehnder, Appl. Environ. Microb. 53 (1987) 1893.

[4] M. Rosenberg, Cr. Rev. Microbiol. 18 (1991) 159.

[5] M.F. Loughlin, M.V. Jones, P.A. Lambert, J. Antimicrob. Chemoth. 49 (2002) 631.

[6] R. Bos, H.J. Busscher, Colloid. Surface. B. 14 (1999) 169.

[7] Y. Zhang, R.M. Miller, Appl. Environ. Microb. 60 (1994) 2101.

[8] Y. Prabhu, P.S. Phale, Appl. Microbiol. Biot. 61 (2003) 342.

[9] M.J. Gross, B.E. Logan, Appl. Environ. Microb. 61 (1995)

[10] T.A. Camesano, K.M. Unice, B.E. Logan, Colloid. Surface. A. 161 (1999) 291.

[11] H.C. van der Mei, A.H. Weerkamp, H.J. Busscher, J. Microbiol. Meth. 6 (1987)

[12] H.J. Busscher, B.v.d. Belt-Gritter, H.C. van der Mei, Colloid. Surface. B. 5 (1995) 111.

[13] G.I. Geertsema-Doornbusch, H.C. van der Mei, H.J. Busscher, J. Microbiol. Meth. 18 (1993) 61.

[14] M. Rosenberg, FEMS Microbiol. Lett. 262 (2006) 129.

[15] M. Hermansson, Colloid. Surface. B. 14 (1999) 105.

[16] R. Bos, H.C. van der Mei, H.J. Busscher, FEMS Microbiol. Rev. 23 (1999)

[17] K.G. Marinova, R.G. Alargova, N.D. Denkov, O.D. Velev, D.N. Petsev, I.B. Ivanov, R.P. Borwankar, Langmuir. 12 (1996)

[18] L.Y. Clasohm, I.U. Vakarelski, R.R. Dagastine, D.Y.C. Chan, G.W. Stevens, F. Grieser, Langmuir. $23(2007) 9335$.

[19] L.S. Dorobantu, A.K.C. Yeung, J.M. Foght, M.R. Gray, Appl. Environ. Microbiol. 70 (2004) 6333.

[20] K. Hori, H. Watanabe, S. Ishii, Y. Tanji, H. Unno, Appl. Environ. Microb. 74 (2008)

[21] G.J. Zylstra, D.T. Gibson, J. Biol. Chem. 264 (1989) 14940.

[22] W.F. Guerin, G.E. Jones, Appl. Environ. Microb. 54 (1988) 937.

[23] I.Y. Jimenez, R. Bartha, Appl. Environ. Microb. 62 (1996) 2311.

[24] R.S. Norman, R. Frontera-Suau, and P.J. Morris, Appl. Environ. Microb. 68 (2002) 5096.

[25] M. Coates, D.W. Connell, D.M. Barron, Environ. Sci. Technol. 19 (1985) 628.

[26] N. Iwabuchi, M. Sunairi, H. Anzai, H. Morisaki, M. Nakajima, Colloid. Surface. B. 30 (2003) 51.

[27] M. Elimelech, J. Gregory, X. Jia, R.A. Williams. Colloid Surface Eng. Series, ButterworthHeinemann, Oxford, 1998.

[28] C.R.W. Zoueki, Thesis, McGill University, 2009.

[29] D.E. Tambe, M.M. Sharma, Adv. Colloid Interfac. 1994 (1994) 1.

[30] J.H. Schulman, J. Leja, T. Faraday Soc. 50 (1954) 598. 


\section{LIST OF FIGURES}

1. FIGURE 1. (a) Fraction of cells partitioned to the hydrocarbon phase measured using classical MATH assay, and (b) fraction of cells partitioned to the hydrocarbon phase measured using the modified MATH protocol. Bacterial suspensions are contacted with either hexadecane $(\mathrm{H})$ or a 50/50 hexadecane/toluene mixture $(\mathrm{HT})$. Cells were suspended in $0.2 \mathrm{mM} \mathrm{NaCl}$ at $\mathrm{pH} 6$ for all measurements $(5$ replicate measurements were made for each experimental condition).

2. FIGURE 2. (a) Microscope image of hydrocarbon droplets stabilized in a Mycobacterium kubicae suspension $(0.2 \mathrm{mM} \mathrm{NaCl}, \mathrm{pH}$ 6) after phase separation step in MATH assay. (White cells are slightly out of focus). (b) Microscope image of hydrocarbon droplets stabilized in a suspension of Pseudomonas putida placed on a Helber cell counting chamber $(0.2 \mathrm{mM} \mathrm{NaCl}, \mathrm{pH} 6)$ after phase separation step in MATH assay. White arrows point to hydrocarbon droplet. Black arrows point to bacterial cells.

3. FIGURE 3. (a) Fraction of Pseudomonas putida cells partitioned to the hydrocarbon phase measured using classical MATH assay, and (b) fraction of Pseudomonas putida cells partitioned to the hydrocarbon phase measured using modified MATH protocol. Cells were suspended in $20 \mathrm{mM} \mathrm{NaCl}$ at $\mathrm{pH} 6$ for all measurements.

4. FIGURE 4. Microscope image of hydrocarbon droplets stabilized in Pseudomonas putida cell-free supernatant $(0.2 \mathrm{mM} \mathrm{NaCl}, \mathrm{pH}$ 6) after phase separation step in MATH assay. 
